\title{
Estratégias de professoras de educação infantil para resolução de conflitos entre crianças
}

\author{
Diana Leonhardt dos Santos \\ Universidade Federal do Rio Grande do Sul - RS \\ Andressa Carvalho Prestes \\ Universidade Federal do Rio Grande do Sul - RS \\ Lia Beatriz de Lucca Freitas \\ Universidade Federal do Rio Grande do Sul - RS
}

\begin{abstract}
Resumo
A educação infantil possui um papel importante no desenvolvimento moral das crianças. O objetivo deste estudo foi examinar se as estratégias propostas por professoras de escolas de Educação Infantil para a resolução de conflitos favorecem o desenvolvimento da heteronomia ou da autonomia moral das crianças. Participaram desta pesquisa dez professoras, cujas idades variavam entre 21 e 41 anos. Utilizaram-se como instrumentos: (a) um questionário sobre formação e trabalho das educadoras; e (b) uma entrevista semiestruturada, na qual se apresentaram duas situações de conflito entre crianças. As respostas das participantes foram submetidas a uma análise de conteúdo. As professoras propuseram tanto estratégias para o desenvolvimento da heteronomia moral quanto estratégias para o desenvolvimento da autonomia moral, embora estas últimas tenham sido menos frequentes. Discutiram-se as implicações destes dados para a educação moral de crianças pequenas e as contribuições deste estudo para o aperfeiçoamento da formação de professoras de Educação Infantil.
\end{abstract}

Palavras-chave: Desenvolvimento moral, conflito, educação Infantil.

\section{Early childhood teachers strategies for resolving children's conflicts}

\begin{abstract}
Early childhood education plays an important role in children's moral development. The objective of this study is to examine whether the strategies proposed by early childhood teachers to resolve their children's conflicts encourages the development of children's heteronomy or moral autonomy. Ten teachers, aged from 21 to 41, participated in this study. The instruments that were used included: (a) a questionnaire about the teachers' training and their work and (b) a semi-structured interview, in which we present two situations featuring conflict among children. The participants' responses were content-analysed. The teachers proposed both strategies likely to lead to the development of moral heteronomy and strategies likely to lead to the development of moral autonomy, although the latter were less frequent. We discuss the relevance of these data for the moral education of young children and the contribution of this study for improving early education teachers' training.
\end{abstract}

Keywords: Moral development, conflict, early childhood education

\section{Estrategias de profesoras de Educación Infantil para la resolución de conflictos entre niños}

\begin{abstract}
Resumen
La educación infantil desempeña un papel importante en el desarrollo moral de los niños. El objetivo de este estudio fue examinar si las estrategias propuestas por profesoras de escuelas de Educación Infantil para la resolución de conflictos favorecem el desarrollo de la heteronomía o de la autonomía moral de los niños. Participaron de la investigación diez profesoras, con edades entre 21 y 41 años. Se utilizaron como instrumentos: 1- un cuestionario sobre formación y trabajo de las educadoras; y 2- una entrevista semiestructurada, en la que se presentaron dos situaciones de conflicto entre niños. Las respostas de las participantes pasaron por análisis de contenido. Las profesoras presentaron propuestas tanto con estrategias destinadas para el desarrollo de la heteronomía moral como con estrategias para el desarrollo de la autonomía moral, sin embargo estas últimas fueron menos frecuentes. Se discuten las repercusiones de estos datos en la educación moral de niños pequeños y las contribuciones de este estudio para el perfeccionamiento de la formación de profesoras de Educación Infantil.
\end{abstract}

Palabras Clave: desarrollo moral; conflicto; educación infantil. 


\section{Introdução}

No mundo atual as crianças em idade pré-escolar passam mais tempo longe de casa do que em épocas anteriores. Muitas são as crianças que permanecem várias horas por dia em escolas de Educação Infantil, onde convivem não apenas com adultos, mas também com seus pares. A creche ou a pré-escola, além de ser uma alternativa muitas vezes escolhida pelas famílias para o cuidado de seus filhos (Rapoport\& Piccinini, 2004), possibilita a ampliação da rede de relações que promovem a socialização dos pequenos (Barbosa, 2006).

No Brasil, desde a Lei de Diretrizes e Bases da Educação Nacional n 9.349/96 (1996), a Educação Infantil é um direito da criança. Considerada como a primeira etapa da educação básica, tem como objetivo o desenvolvimento integral da criança até os cinco anos de idade (Lei no 11.114/05) nos aspectos físico, psicológico, intelectual e social. Outro documento importante, o Referencial Curricular Nacional para a Educação Infantil (1998), baseado nas diretrizes da LDB, orienta que as escolas de educação infantil proporcionem o desenvolvimento das crianças em suas capacidades física, cognitiva, afetiva, estética e ética. O documento possui uma preocupação evidente com o desenvolvimento das relações interpessoais e da interação social dos educandos.

Uma pesquisa recente realizada por Pereira, Marturano, Gardinal-Pizato e Fontaine (2011) verificou que crianças que frequentam até um ano de Educação Infantil se mostram mais responsáveis, cooperativas e assertivas do que aquelas que não tiveram acesso a essa etapa do ensino. Além do impacto no desempenho escolar e na competência social dos estudantes, a Educação Infantil desempenha um papel fundamental na formação ética e desenvolvimento moral das crianças (Dias \& Vasconcellos, 1999).

Conforme assinalaram diversos autores (e.g., La Taille, 2006; Lourenço, 1992; Vale \& Alencar, 2008), uma referência importante para os pesquisadores da moralidade humana é a obra do psicólogo e epistemólogo suíço Jean Piaget. De acordo com a teoria construtivista, a moralidade humana não é inata, mas fruto de um desenvolvimento calcado nas interações do indivíduo com o seu meio (Piaget, 1932/1994, 1954, 1965/1977).

Inicialmente, a regra confunde-se com o hábito: a criança não vê diferença entre o que se faz e aquilo que se deve fazer. Piaget (1932/1994) chamou de anomia a este período do desenvolvimento moral. Quando, ao final do período sensório-motor, ocorre uma primeira diferenciação eu-outrem, é possível que os afetos, até então ligados à atividade da própria criança, originem também sentimentos entre os indivíduos, isto é, sentimentos interindividuais, tais como os de respeito e de dever (Freitas, 1999).

Por volta dos 3 a 4 anos, em média, a criança passa a entender que existem coisas que devem ser feitas e outras que não se devem fazer (La Taille, 2006). A partir de então, a obediência às normas é tomada como certa, como uma extensão do respeito que a criança nutre pelas autoridades que elas reconhecem com tal (pais, professores e demais adultos significativos para ela). Denomina-se de unilateral a essa forma de respeito, pois há uma submissão dos pequenos aos mais velhos, caracterizando a coação destes em relação àqueles. Piaget (1932/1994) chamou de heteronomia a este tipo de moral, uma vez que as regras provêm dos outros e são obedecidas por motivos externos à consciência da criança.

A heteronomia pode ser superada e dar lugar à autonomia moral, quando então as regras são seguidas por serem tidas como necessárias ao convívio social. Em outras palavras, a criança pode internalizar as normas, compreender o porquê da sua existência, tornando-se gradualmente capaz de se autorregular. Segundo Piaget (1932/1994), isto é possível graças às trocas que a criança experimenta com seus pares. Na medida em que se estabelecem relações simétricas, isto é, entre iguais, desenvolve-se outra forma de relação social: a cooperação. Por meio das relações cooperativas, o respeito unilateral é superado pelo respeito mútuo, o qual possibilita que cada indivíduo se coloque no lugar do outro.

Entende-se que a heteronomia, apesar de suas limitações, é uma etapa fundamental para o desenvolvimento moral, uma vez que fornece as bases sobre as quais se assentam formas mais sofisticadas dos sentimentos de respeito e de dever (Freitas, 1999; La Taille, 2006).Não obstante, somente a coação não é suficiente para superar o egocentrismo infantil (Piaget, 1930/1998; 1932/1994), ou seja, a criança heterônoma não é capaz de descentrar-se para se colocar no lugar do outro, o que constitui uma limitação para a vivência em sociedade. É a cooperação que leva à formação do sentimento genuíno de seguir uma norma por dever (e não apenas conforme o dever) ${ }^{1}$ e à habilidade de coordenar diferentes pontos de vista para, por exemplo, agir de maneira justa.

Dependendo do tipo de educação que a criança receba, enfatiza-se mais uma moral do que a outra. Piaget (1930/1998) distingue basicamente dois métodos de educação moral: (a) o método verbal; e (b) o método ativo. O primeiro consiste em ensinar as noções de moral e valores às crianças através de discursos e sermões, enquanto o método ativo busca não impor à criança por meio da autoridade aquilo que ela tem condições de descobrir por si mesma aointeragir com outras pessoas. Piaget considera que, sozinho, o método verbal não é capaz de fazer a criança internalizar o porquê das regras, pois ensina regras prontas, as quais assim se relacionam à coação e ao respeito unilateral. Somente com a participação ativa da criança em ações e reflexões que digam respeito a questões morais é que sua autonomia pode desenvolver-se.

Considerando-se que as relações sociais de coação e de cooperação são fundamentais para o pleno desenvol-

\footnotetext{
1 Segundo a tradição kantiana, agir moralmente é agir por dever, ou seja, é moral apenas a ação que não se possa explicar por outra razão senão o sentimento de dever. Assim, uma ação conforme o dever não necessariamente tem um valor moral. Pode-se agir conforme o dever, por exemplo, para receber um benefício, por medo, etc.
} 
vimento moral do ser humano, entende-se que as escolas de Educação Infantil são instituições importantes para esse desenvolvimento, visto que são espaços ricos em relações interpessoais;no entanto, não raras vezessurgem nessas escolas situações de conflito.

Conflitos são inerentes à condição humana (Freitas, 2011) e acontecem em todas as instituições educativas (Carina \& Assis, 2011). O professor pode tentar evitar o surgimento de conflitos, seja realizando atividades dirigidas seja separando a turma, ou ainda intervindo rapidamente para resolver o problema (Vinha, 2004); no entanto, perde-se assim a oportunidade de trabalhar valores e regras fundamentais para o convívio social. De acordo com Leme (2011), os desacordos que acontecem na interação com o outro permitem, por exemplo, que um indivíduo conheça um ponto de vista diferente do seu, por isso se deve levar em conta a perspectiva do outro para se chegar a uma resolução cooperativa. Estas situações, segundo Leme, permitem que a criança perceba que o outro também possui sentimentos, ideias e desejos. Neste mesmo sentido, Dani (2009) argumenta que, quando os conflitos são problematizados e discutidos de forma construtiva, amplia-se a possibilidade de cooperação, de superar relações de caráter individualista e competitivo e de construir conjuntamente formas pacíficas de convivência.

Vários estudos recentes sobre a resolução de conflitos e sua relevância para o desenvolvimento moral enfocam situações que ocorrem com crianças em idade escolar e/ou adolescentes (e.g., Araújo, 2008; Baroni\&Frick, 2011; Carina \& Assis, 2011; Dani, 2009; Oliveira, 2011; Vinha, 2003); no entanto, conflitos entre crianças são também bastante frequentes nas escolas de Educação Infantil (e.g., Morais \&Otta, 2008; Sager\&Sperb, 1998; Trevisol\&Toigo, 2011).

Marimon e Vilarrasa (2005) consideram que as crianças devem começar desde cedo a aprender a resolver os conflitos que surgem no seu dia a dia. Neste caso, muitas vezes a intervenção do professor/adulto énecessária para ajudá-las a lidar com a situação conflituosa de forma satisfatória, uma vez que são limitados os seus recursos cognitivos e afetivos (Trevisol\&Toigo, 2011).

As estratégias de professores para a resolução de conflitos demonstram suas concepções sobre esse fenômeno (Carina \& Assis, 2011; Vinha, 2004). Além disto, as intervenções realizadas pelos educadores provocam nos educandos consequências significativas para a construção de regras e valores (Maya, 2005), podendo favorecer tanto o desenvolvimento da moral da heteronomiaquantoa autonomia moral das crianças.

É importante examinar as maneiras como se tem lidado com essas situações, principalmente por três razões, a saber: 1- as situações de conflito entre crianças são frequentes em escolas de educação infantil; 2- o educador exerce um papel importante na resolução de conflitos; e 3- as estratégias utilizadas pelos professores na resolução de conflitos podem favorecer o desenvolvimento da heteronomia ou da autonomia moral. Considerando-se este fato, desenvolveu-se um estudo com objetivo de investigar se as estratégias de resolução de conflitos utilizadas por professoras que atuam em escolas de Educação Infantil estão voltadas para o desenvolvimento da heteronomia ou da autonomia moral das crianças.

\section{Método}

\section{Participantes}

Dez professoras titulares de turma de escolas particulares de educação infantil da cidade de Porto Alegre integraram a amostra deste estudo. Os critérios de inclusão foram: (a) a professora ter a idade mínima de 18 anos; (b) ser professora titular de turma; e (c) ser formada no curso de Pedagogia ou estar cursando o último ano da graduação. As professoras tinham entre 21 e 41 anos de idade. Dentre as participantes, oito possuíam Ensino Superior completo em pedagogia, com formação entre os anos de 1991 e 2011, e duas estavam no último ano do curso. Ainda no tocante à formação, cinco professoras tinham o curso de Magistério, duas, o curso de educadora assistente, e três haviam feito pós-graduação em Educação. Cada participante trabalhava em apenas uma das quatro escolas de Porto Alegre queparticiparam da pesquisa, sendo professoras titulares nas seguintes turmas: uma de berçário II (crianças de um a dois anos de idade), duas de maternal I (dois a três anos), três de maternal II (três a quatro anos), uma de maternal III e jardim (quatro a seis anos) e três de jardim (cinco a seis anos). Da amostra total, quatro professoras trabalhavam na escolanos dois períodos (manhã e tarde), enquanto as demais, em apenas no período da tarde.

\section{Instrumentos}

Utilizaram-se dois instrumentos: 1- questionário sobre formação e trabalho das educadoras (Lapege, 2010a); e 2- entrevista semiestruturada (Lapege, 2010b). Nesta entrevista, tal como propõe Dias (2001), foram investigados temas relacionados ao desenvolvimento moral e à educação para autonomia. Além disto, inclui-se uma pergunta sobre duas situações de conflito, a fim de examinar como as professoras agiriam nessas situações.Neste artigo são analisadas as respostas das participantes à pergunta: "O que você faria diante das seguintes situações:"

- primeira situação: duas crianças de sua turma estão brigando por causa de um brinquedo da escola;

- segunda situação: algumas crianças estão brincando juntas e outro colega, que estava fora da brincadeira, pergunta se poderia participar, e os colegas respondem que não"?.

Essas situações de conflito foram imaginadas e elaboradas pela primeira autora, inspirada em Araújo (2008) e Vinha (2003) em sua própria experiência profissional como psicóloga em escolas de Educação Infantil. 


\section{Delineamento e procedimentos}

Este é um estudo descritivo (Colin, 1993) e nele se priorizou a análise qualitativa dos dados. Utilizou-se também um levantamento de frequências, o qual auxiliou na apresentação e discussão dos resultados. A pesquisa foi aprovada pelo Comitê de Ética em Pesquisa do Instituto de Psicologia da Universidade Federal do Rio Grande do Sul (Protocolo número 2011029),garantindo os direitos e deveres relativos aos participantes e à comunidade científica. As diretoras das instituições de ensino assinaram a autorização para a realização da pesquisa e as participantes assinaram o Termo de Consentimento Livre e Esclarecido.

O questionário foi preenchido pelas próprias participantes no mesmo dia em que se realizou a entrevista. As entrevistas foram gravadas e posteriormente transcritas para análise. Para preservar a identidade das professoras entrevistadas, atribuíram-se nomes fictícios às participantes.

Seguiram-se os seguintes passos na análise de conteúdo (Bardin, 1977) das respostas: 1-identificaram-se e listaram-se as estratégias que surgiram no discurso das professoras em relação à situação 1; 2- agruparam-se as respostas em categorias provisórias; 3- adotaram-se os mesmos procedimentos para analisar a situação 2; 4compararam-se as categorias provisórias da situação 1 e da situação 2 e redefiniram-se as categorias provisórias, de forma que dessem conta de ambas as situações, construindo-se, assim, as categorias de análise; 5-identificaram-se subcategorias dentro de cada categoria; 6 - dois juízes leram independentemente todas as estratégias citadas pelas participantes, em ambas as situações, classificando-as nessas categorias e subcategorias; em caso de desacordo (em onze estratégias), cada juiz apresentou seu ponto de vista e chegou-se a um acordo. Após terem-se classificado as respostas das participantes de acordo com as categorias e subcategorias, realizou-se um levantamento de frequência. Uma mesma participante pode ter mencionado mais de uma estratégia para resolver as situações de conflito.

\section{Resultados}

Apresentam-se, a seguir, as categorias e subcategorias de análise das respostas das participantes:

1. Estratégias voltadas para a heteronomia, as quais se referem: (a) aos métodos orais de educação moral - lição de moral (LM);e (b) as ações ou comandos que visam extinguir o conflito (EC), ao menos momentaneamente. Estas estratégias pressupõem uma figura de autoridade - neste caso, a professora -, a qual determina as ações das crianças sem procurar engajá-las no processo de resolução do conflito. Em outras palavras, a professora apresenta uma solução "pronta" para o conflito: ela resolve esse conflito pelas crianças.
2. Estratégias voltadas para a autonomia: referem-se aos métodos ativos de educação moral. A professora procura implicar as próprias crianças na busca de uma solução para o conflito: (a) ela apresenta alternativas $(\mathrm{AL})$ para que as crianças reflitam juntamente com ela sobre a situação e cheguem a uma solução conjunta; ou (b) ela propõe situações de cooperação (CO), favorecendo a interação entre as crianças. Em síntese, de uma forma ou de outra, a professora incentiva a participação das crianças na resolução do problema, ou seja, ela busca resolver o conflito juntamente com as crianças.

Essas duas formas de resolver os conflitos entre crianças apareceram em ambas as situações propostas às participantes. Apresentam-se, a seguir, trechos de entrevistas que ilustram essas categorias e suas respectivas subcategorias.

Quanto às estratégias voltadas para a heteronomia, constatou-se que ummeio sugerido pelas participantes de resolver conflitos foi a lição de moral (LM), em que a professora busca mostrar o certo e o errado às crianças por meio do discurso. Por exemplo:

"Primeiro, eu ia falar pra eles que o brinquedo é de todos, então é pra todo mundo brincar junto. E sabe que funciona? Eles falam: "Ô, o brinquedo é da escola, é pra todo mundo brincar junto, então eu quero brincar contigo". Eles convidam: "Deixa eu brincar contigo?";e aí eles lembram que o brinquedo é da escola, e eles acabam brincando juntos". (Isadora, situação 1)

\footnotetext{
“A primeira pergunta da professora Maria: 'Por que não?'. Aí alguns vão sair com algum argumento, né... 'Não, o colega quer brincar, ele pode brincar sim junto. Imagina se o colega tá com outra turma e um de vocês quer entrar e ele não vai querer? Tu vai ficar feliz de ser excluído, de não deixarem?'”. (Maria, situação 2)
}

Ainda em relação às estratégias voltadas para a heteronomia, observou-se outro modo de solução de conflitos presente nas respostas das professoras: determinar ações a serem realizadas pelas crianças ou dar comandos que visem à extinção do conflito (EC). Leia-se o exemplo abaixo:

\footnotetext{
"Se o brinquedo não pode ser compartilhado, 'Quem foi que pegou primeiro?'. Aí, um vai se pronunciar, ou não: 'É meu, é meu! Fui eu!'. Se os dois disserem que sim, então: 'Agora eu vou guardar esse brinquedo e a gente vai pegar um outro pra brincar juntos, ou cada um escolhe o seu pra brincar, mas esse aqui, agora, não"'”. (Elisa, situação 1)

"Agora, se for um jogo que tem uma rodada específica: 'Tu vai esperar a tua vez, porque ainda não tá na hora de entrar. Espera e depois, na próxima rodada, tu entra'”. (Elisa, situação 2)
} 
Quanto às estratégias voltadas para a autonomia, também distinguiram-se dois modos de resolver conflitos. O primeiro modo proposto pelas participantes consistiu na apresentação de alternativas $(A L)$ para que a criança participe da resolução do conflito, conforme exemplificam as seguintes respostas:

"Primeiro eu chamaria as duas crianças, perguntaria o porquê que eles tão brigando, e diria que ou eles brincam juntos com o brinquedo da escola, ou um vai brincar um pouquinho... Quem pegou primeiro vai brincar um pouquinho, um tempo que eu vou marcar no relógio, e depois desse tempo o outro vai brincar um pouquinho com o brinquedo." (Luana, situação 1).

"Às vezes a criança quer brincar; já tem um grupo ali... Às vezes eu fico em dúvida: será que eu interfiro ou não? Tem essa questão também. Eles tão brincando já, aí vem um... Eu sempre estimulo, até pra não frustrar a criança. Eu sempre estimulo que eles conversem. Na etapa em que eles estão agora, geralmente eles resolvem; eles conversam e aceitam que o outro brinque. Só que às vezes o outro não quer aceitar as regras, 'Então, não vai poder brincar, porque eles já construíram a regra da brincadeira antes de tu chegar. Então, ou tu aceita, ou dá outras ideias, ou tu não brinca"'. (Cristina, situação 2)

A segunda forma foi a promoção de relações cooperativas $(\mathrm{CO})$ entre as crianças. Por exemplo:

"Se for um brinquedo de montar, como tem muitos na sala, 'Vão montar juntos.Chegou essa peça, Fulaninho pega essa outra peça, vamos encaixar juntos, vamos ver o que vai sair desse brinquedo, vamos fazer alguma coisa, vamos construir algo." (Maria, situação 1).

"Normalmente, eles me chamam, eles não ficam tristes e vão pro canto chorar.Sempre que se chateiam eles vêm ao meu encontro. Aí é ir lá com ela, perguntar qual é a brincadeira, dizer que ela quer brincar. Aí eles já dizem o motivo, por exemplo: 'A Júlia não sabe brincar dessa brincadeira'. 'Então ensina pra Júlia, ensina pra profe que a profe vai brincar um pouquinho com vocês'. E, claro, sempre que eu me insiro na brincadeira, todo mundo quer brincar junto. Aí depois eu saio e digo: 'Agora a Júlia vai ser o que a profe era'. E aí ela sempre ganha os melhores papéis. 'Agora a Júlia vai ficar no meu lugar'. Aí eu saio da brincadeira e elas continuam, conseguem aceitar no grupo." (Luana, situação 2).

$\mathrm{Na}$ tabela 1 se apresentam as frequências de respostas das participantes distribuídas nessas categorias e subcategorias, em ambas as situações de conflito.

\section{Discussão}

Neste artigo foram examinadas estratégias propostas por professoras de escolas de Educação Infantil de Porto Alegre para resolver duas situações de conflito entre crianças no contexto escolar. Constatou-se que em ambas as situações as professoras propuseram com maior frequência estratégias nas quais elas mesmas, enquanto figuras de autoridade, buscaram ensinar, através do discurso, como se deve agir com o outro, ou determinaram a maneira como as crianças deviam agir. Essas condutas promovem mais a obediência da criança do que sua autonomia moral, fato que ocorre mesmo quando a professora busca transmitir apenas por meio do método verbal um conteúdo que poderia fomentar a moral da autonomia. Este é o caso, por exemplo, da professora Maria, a qual propõe às crianças que se imaginem no lugar do colega excluído da brincadeira (situação 2). Conforme ressaltou Piaget (1930/1998), "a 'lição de moral' não deve ser proscrita" (p. 42), mas o ensino puramente oral do adulto não promove a autodescentração da criança, uma vez que as relações de coação entre adulto e criança são insuficientes para retirar a criança de seu egocentrismo. Entende-se que no qual predomine a autoridade do adulto, ou seja, um ambiente marcapelorespeito unilateral, fortalece a heteronomia da criança (Piaget, 1930/1998; Vinha, 2004).

Tabela 1. Frequência dos Tipos de Estratégia de Resolução de Conflito.

\begin{tabular}{lccccc}
\hline & Heteronomia & & Autonomia & Total \\
\hline & LM & EC & AL & CO & \\
\hline Situação 1 & 1 & 11 & 4 & 4 & 20 \\
Situação 2 & 7 & 2 & 2 & 3 & 14 \\
\hline Total & 8 & 13 & 6 & 7 & 34 \\
\hline
\end{tabular}


Pode-se pensar que isso se deva ao fato de que essas professoras trabalham com crianças pequenas (crianças de um a seis anos de idade) e talvez acreditem que seja necessário dizer às crianças o que fazer diante de um impasse. As relações de coação, baseadas no respeito unilateral, são necessárias e até mesmo inevitáveis nos primeiros anos do desenvolvimento moral infantil (Freitas, 1999; La Taille, 2006; Piaget, 1932/1994);mas isto não significa que os procedimentos de educação moral (Piaget, 1930/1998) devam basear-se apenas nesse tipo de relação. A relação assimétrica entre adulto e criança não impede que se realize uma educação que promova o desenvolvimento da autonomia moral. Se o professor tiver uma postura impositiva, esta postura fomentará a moral da heteronomia; mas se ele buscar promover a cooperação e o respeito mútuo, contribuirá para a construção da autonomia moral da criança (Müller \& Alencar, 2012).

Outra explicação possível para os resultados encontrados é que as professoras busquem resolver as situações de conflito entre crianças de forma intuitiva. Esta é uma explicação plausível, visto que raramente os cursos de formação proporcionam a reflexão sobre questões sociais e éticas, de forma a preparar o futuro profissional para, com segurança e tranquilidade, intervir em situações de divergências e disputas e resolvê-las (Barrios, Marinho-Araújo, \& Branco, 2011; Vinha, 2004; Vinha \&Tognetta, 2009). Assim, talvez as professoras ensinem seus alunos a resolver conflitos como elas mesmas foram ensinadas a resolvê-los. Conforme sugeriram Müller e Alencar (2012), se conteúdos relativos à moralidade humana não são incluídos nos cursos de formação de professores, é bem provável que eles ensinem da forma como aprenderam "(...) em casa, com seus pais; na escola, com seus professores; no trabalho, com seus colegas e com seus alunos; entre outras situações" (p. 457). Devido à formação precária, o trabalho pedagógico das educadoras fica alicerçado no senso comum, e não numa teoria ou estudo cientifico sério e consistente (Lima, 2003). Dani (2009) corrobora essas ideias e acrescenta que uma formação científica e humanizada conduz a professora a pesquisar, a questionar sua prática, sua postura e suas limitações.

Cabe destacar que várias professoras sugeriram mais de uma estratégia para uma mesma situação de conflito, algumas voltadas para a heteronomia e outra(s) para a autonomia. Quando uma tentativa não dava certo, utilizavam outra mais diretiva. Este dado sugere que as educadoras não têm consciência de que não são apenas duas as formas de resolução de conflitos, mas que esses diferentes tipos de estratégia contribuem para o desenvolvimento de duas morais distintas na criança: a moral heterônoma e a moral autônoma.

Como Marimon e Vilarrasa (2005), considera-se que as crianças devam começar desde pequenas a aprender a resolver os conflitos que surgem no seu cotidiano. Neste sentido, embora tenham sido menos frequentes, as estratégias voltadas para a autonomia sugeridas pelas professoras neste estudo são muito importantes, pois indicam que isso é possível. Quando propõe alternativas às crianças ou promove relações cooperativas entre elas, a professora as incentiva a participar na solução do conflito eassim as ajuda a controlar seus impulsos e a considerar o ponto de vista e os sentimentos dos outros (Vinha, 2004). Nesta perspectiva, a professora é uma mediadora da situação (Carina \& Assis, 2011) e sabe que os conflitos fazem parte do cotidiano da criança, sendo considerados pertinentes e necessários para o seu desenvolvimento.

É importante salientar algumas limitações desta pesquisa. A primeira limitação refere-se ao pequeno número de participantes e à heterogeneidade da amostra (número de anos de experiência profissional e idade das crianças com as quais trabalham). Outra limitação diz respeito ao fato de que se teve acesso apenas ao as professoras disseram sobre como resolveriam as situações de conflito com que se deparavam. Buscou-se, desta forma, conhecer mais e melhor a prática profissional, sem limitar-se apenas a algo abstrato e conceitual. Além disso, tem-se consciência de que suas respostas podem não corresponder àquilo que realmente fazem no seu dia a dia. Esta limitação do estudo poderia ser contornada se fossem feitas observações sistemáticas.

Apesar disso, considera-se que o tema da investigação é pertinente e atual, dado o número crescente de educadores que se deparam com as mais diversas situações de conflito, violência e desrespeito dentro das escolas. Este artigo apresenta resultados de um estudo que enfocou especificamente situações de conflito entre crianças em idade pré-escolar que, embora sejam bastante frequentes, não tinham sido abordados nas pesquisas recentes sobre a resolução de conflitos e sua relevância para o desenvolvimento moral.

\section{Referências}

Araújo, U. F. (2008). Resolução de conflitos e assembleias escolares. Cadernos de Educação, 31, 115-131.

Barbosa, M. C. S. (2006). Por amor e por força: Rotinas na educação infantil. Porto Alegre: Artmed.

Bardin, L. (1977). Análise de conteúdo. São Paulo: Martins Fontes.

Baroni, M. C. S., \& Frick, L. T. (2011).A justiça restaurativa como instrumento de resolução de conflitos escolares. Caderno de resumos e programação do II Congresso de Pesquisas em Psicologia e Educação Moral. Recuperado: 09 fev 2012. Disponível: http://www.fe.unicamp.br/coppem/index.php/anais-2011/

Barrios, A., Marinho-Araujo, C. M., \& Branco, A. U. (2011). Formação continuada do professor: Desenvolvendo competências para a promoção do desenvolvimento moral. Revista Semestral da Associação Brasileira de Psicologia Escolar e Educacional, 15(1), 91-99.

Carina, S. C., \& Assis, O. Z. M. (2011). O processo de resolução de conflitos entre pré-adolescentes: O olhar do professor.Caderno 
de resumos e programação do /l Congresso de Pesquisas em Psicologia e Educação Moral. Recuperado: 09 fev 2012. Disponível: http://www.fe.unicamp.br/coppem/index.php/anais-2011/

Colin, R. (1993). Real world research: A resourse for social sciences and practioner-researcher.Oxford: Blackwell.

Dani, L. S. C. (2009). Conflitos, sentimentos e violência escolar. Revista Psicologia Educacional, 9(28), 571-586.

Dias, A. A. (2001). A autonomia enquanto fundamento da educação moral na educação infantil: Concepções e práticas. Tese de Doutorado, Curso de Pós-Graduação em Educação da Universidade Federal Fluminense, Niterói, RJ.

Dias, A. A., \& Vasconcellos, V. M. R. (1999). Concepções de autonomia dos educadores infantis. Temas em Psicologia, 07(1), 9-21.

Freitas, L. B. L. (1999). Do mundo amoral à possibilidade de ação moral. Psicologia: Reflexão e Crítica, 12(2), 447-458.

Freitas, L. B. L. (2011). Vontade: Instrumento de autorregulação em situações de conflito. Caderno de resumos e programação do Il Congresso de Pesquisas em Psicologia e Educação Moral. Recuperado: 09 fev 2012. Disponível:http://www.fe.unicamp.br/ coppem/index.php/anais-2011/

La Taille, Y. (2006). A importância da generosidade no inicio da gênese da moralidade na criança. Psicologia Reflexão e Crítica, 19(1), 9-17.

Lapege - Laboratório de Psicologia e Epistemologia Genética. (2010a). Questionário sobre formação e trabalho das educadoras. Instrumento não-publicado, Instituto de Psicologia, Universidade Federal do Rio Grande do Sul.

Lapege - Laboratório de Psicologia e Epistemologia Genética. (2010b). Roteiro de entrevista sobre autonomia. Instrumento nãopublicado, Instituto de Psicologia, Universidade Federal do Rio Grande do Sul.

Lei n. 11.114, de 16 de maio de 2005. (2005). Ministério da Educação e Cultura. Diário Oficial da União,Brasília: MEC.

Lei n. 9.394, de 20 de dezembro de 1996. (1996, 23 de dezembro). Estabelece as Diretrizes e Bases da Educação Nacional. Diário Oficial da União, seção 1.

Leme, M. I. S. (2011). O diretor escolar e a gestão de conflitos na escola. Em: L. R. P. Tognetta\& T. P. Vinha (Eds.), Conflitos na instituição educativa: perigo ou oportunidade?(pp. 161-188). Campinas,SP: Mercado das Letras.

Lima, A. E. O. (2003). A ética e o ensino infantil: O desenvolvimento moral na pré-escola. Dissertação de Mestrado, Universidade Estadual Paulista, Faculdade de Filosofia e Ciências, Marilia, SP.
Lourenço, O. M. (1992). Psicologia do desenvolvimento moral: teoria, dados e implicações. Coimbra, Portugal: Almedina.

Marimon, M. M., \&Vilarrasa, G. S. (2005). Conflitos e emoções: uma aprendizagem necessária. Em: E. Vinyamata (Ed.),Aprendendo a partir do conflito (pp. 65-74). Porto Alegre: Artmed.

Maya, B. M. (2005). Educar para a administração de conflitos como via de aprofundamento da democracia. Em: E. Vinyamata (Ed.),Aprendendo a partir do conflito (pp. 75-83). Porto Alegre: Artmed.

Morais M. L. S., \&Otta, E. (2008). Diferenças culturais e de gênero em conflitos de pré-escolares. Psicologia: Reflexão e Crítica, 21(2), 221-232.

Müller, A., \&Alencar, H. M. (2012). Educação moral: O aprender e o ensinar sobre justiça na escola. Educação e Pesquisa, 38(2), 453-468.

Oliveira, F. C. (2011). Relações entre desenvolvimento moral, agressividade e estilos de resolução de conflitos interpessoais. Caderno de resumos e programação do II Congresso de Pesquisas em Psicologia e Educação Mora/Recuperado: 09 fev 2012. Disponível: http://www.fe.unicamp.br/coppem/index.php/ anais-2011/

Pereira, M. T., Marturano, E. M., Gardinal-Pizato, E. C., \& Fontaine, A. M. G. (2011). Possíveis contribuições da educação infantil para o desempenho e a competência social de escolares. Revista Semestral da Associação Brasileira de Psicologia Escolar e Educacional, 15(1), 101-109.

Piaget, J. (1954). Les relations entre l'affectivitéetl'intelligence.Paris: Sorbonne.

Piaget, J. (1977). Étudessociologiques (3aed). Genève: Droz. (Trabalho original publicado em 1965)

Piaget, J. (1994). O juízo moral na criança. São Paulo: Summus. (Trabalho original publicado em 1932)

Piaget, J. (1998). Os procedimentos da educação moral. Em S. Parrat-Dayan, \& A. Tryphon (Eds.), Sobre pedagogia (pp. 25-58). São Paulo: Casa do Psicólogo. (Trabalho original publicado em 1930)

Rapoport, A., \& Piccinini, C. A. (2004). A escolha do cuidado alternativo para o bebê e a criança pequena. Estudos de Psicologia, 9(3), 497-503

Referencial curricular nacional para a educação infantil. (1998). Ministério da Educação e Cultura. Secretaria de Ensino Fundamental. Brasília: MEC.

Sager, F., \& Sperb, T. M. (1998).O brincar e os brinquedos nos conflitos entre crianças. Psicologia: Reflexão e Crítica, 11(2), 309-326. 
Trevisol, M. T. C., \&Toigo, L. C. (2011). Cenas do cotidiano em discussão na escola: Como agir diante delas? Caderno de resumos e programação do II Congresso de Pesquisas em Psicologia e Educação Moral.Recuperado: 09 fev2012. Disponível:http://www. fe.unicamp.br/coppem/index.php/anais-2011/

Vale, L. G., \& Alencar, H. M. (2008). Juízos morais de crianças e adolescentes sobre ausência de generosidade e punição. Psic, 9(2), 235-244.

Vinha, T. P. (2003). Os conflitos interpessoais na relação educativa. Tese de Doutorado, Programa de Pós-Graduação em Educação, Universidade Estadual de Campinas, SP.
Vinha, T. P. (2004). O processo de resolução de conflitos interpessoais na escola autocrática e democrática. Revista da Faculdade Adventista da Bahia Formadores: Vivências e Estudos, 1(1), 6378.

Vinha, T. P., \& Tognetta, L. R. P. (2009). Construindo a autonomia moral na escola: Os conflitos interpessoais e a aprendizagem de valores. Revista Diálogo Educacional, 9(28), 525-540.

Recebido em: 28/01/2013

Reformulado em: 21/08/2013

Aprovado em: 04/09/2013

\section{Sobre as autoras}

Diana Leonhardt dos Santos (dianna84@ig.com.br)

Psicóloga, Especialista em Psicologia Escolar, Mestre em Psicologia do Desenvolvimento pela Universidade Federal do Rio Grande do Sul.

Andressa Carvalho Prestes (andressa.prestes@ufrgs.br)

Estudante do Curso de Psicologia da Universidade Federal do Rio Grande do Sul, bolsista de Iniciação Científica do CNPq.

Lia Beatriz de Lucca Freitas (Iblf@ufrgs.br)

Doutora em Psicologia, Professora Associada do Instituto de Psicologia e do Programa de Pós-Graduação em Psicologia da Universidade Federal do Rio Grande do Sul, coordenadora do LAPEGE - Laboratório de Psicologia e Epistemologia Genética.

Este artigo é baseado em parte da Dissertação de Mestrado da primeira autora, realizada sob a orientação da terceira. Este trabalho foi desenvolvido no Programa de Pós-Graduação em Psicologia da Universidade Federal de Rio Grande do Sul. A segunda autora colaborou na realização da pesquisa e na redação deste artigo como bolsista de Iniciação Científica do CNPq. Apoio: Programa PIBIC CNPq/UFRGS. 